\title{
The effects of anogenital condylomas on female sexuality and psychology: a case-control study
}

\author{
๑DEser A ğar ${ }^{1}$, @Seda Şahin Aker ${ }^{2}$ \\ ${ }^{1}$ İstanbul Gelişim University, Vocational School of Health Services, Department of Operating Room Services, İstanbul, Turkey \\ ${ }^{2}$ Kayseri City Education and Training Hospital, Department of Gynecologic Oncology, Kayseri, Turkey
}

Cite this article as: Ağar E, Şahin Aker S. The effects of anogenital condylomas on female sexuality and psychology: a case-control study. J Health Sci Med 2021; 4(4): 482-487.

\begin{abstract}
Aim: Human Papillomavirus is a sexually transmitted virus with over two hundred subtypes. It can cause anogenital condyloma, cervical dysplasia, and cervical cancer. Human Papillomavirus types 6 and 11 are responsible for anogenital condylomas. The effect of condylomas on female sexual life and psychological state is investigated in our study.

Material and Method: Seventy-six vulvar condyloma patients and 80 participants as the control group were included in the study after excluding the subjects not meeting the inclusion criteria. After an initial evaluation, condylomas excised using carbon dioxide laser followed by a medical assessment in the 3rd post-excisional month. Female sexual function index and Beck depression inventory scales were used on a group of healthy patients with anogenital condyloma at 0-3 months.

Results: There was a statistically significant difference in the FSFI scores at 0 and 3 months between the case and control groups $(\mathrm{p}<0,001)$. Although no statistically significant difference was found, a trend of improvement in the Female sexual function index scores of cases from 0 to 3 months was observed $(p=0.194)$. A statistically significant difference was found in the Beck depression inventory scores of cases from 0 to 3 months $(p=0.002)$.

Conclusion: Anogenital condylomas cause negative effects on female psychology and sexuality, and excisional intervention seems to have a beneficial effect on psychology and sexual functions.
\end{abstract}

Keywords: HPV, condyloma, sexual functioning, depression

\section{INTRODUCTION}

Human Papillomavirus (HPV) infection, which is the most common sexually transmitted disease worldwide, affects the skin and mucosal surfaces and can cause anogenital condylomas, cervical intraepithelial neoplasia, and cervical cancer (1). More than $200 \mathrm{HPV}$ subtypes that show tropism to different body parts have been identified (2). Cutaneous warts on hands and feet are mostly caused by HPV 1, 2, 4, 27, or 57 subtypes (3). HPV 6 and 11 subtypes that are called low-risk HPV are responsible for anogenital condylomas (4). The prevalence of anogenital warts in women aged 30-65 was found to be $154 / 100,000$ in Turkey (5). Anogenital localization of condylomas has a negative effect on female sexuality. It may challenge the loyalty of the couple to each other and affect their sexual functions (6). The condylomas have a recurrence rate of $15-37 \%$ even after excision (5). The presence of condylomas, frequent recurrences, and consequent repetitive treatments can lead to vulvodynia and dyspareunia (7). The recent screening programs for
HPV in some countries led to a significant increase in the diagnostic rate of HPV. Although studies have been conducted to determine whether there is a relationship between HPV infection, precancerous lesions, and sexual life, there is a limited number of studies on the effects of anogenital condylomas on sexual and psychological life.

In this study, we aimed to evaluate the sexual functions and psychological status of women diagnosed with anogenital condyloma and infection with low-risk HPV types.

\section{MATERIAL AND METHOD}

This cross-sectional study was approved by the İstanbul Gelişim University Ethics Committee (Date: 11.09.2020, Decision No: 2020-24-03). All procedures were carried out in accordance with the ethical rules and the principles of the Declaration of Helsinki. Before the study, all participants were informed, and written consent was obtained. 
Sexually active patients aged $18-45$, who were diagnosed with anogenital condyloma in a private health facility in the district of Silivri in Istanbul between February 2020 and January 2021, and sexually active volunteers of reproductive age without any health problems were included in the study. Patients with known chronic conditions, such as psychiatric, neurological, endocrinological, cardiological, and renal diseases, and patients with at least one incident of recurrent condyloma were excluded from the study.

Ninety-two patients diagnosed with vulvar condyloma were included in the study. Initially, the lesions were examined by inspection. A biopsy was taken from the condyloma. HPV PCR test and histopathological examination were performed on the sample taken for differential diagnosis. Finally, the condylomas were destroyed using fractional carbon dioxide laser. DNA of the samples was isolated with Magnesia Viral Nucleic Acid Extraction kit and HPV DNA PCR method was performed with Montania 4896 Real-Time PCR device. $100 \mathrm{HPV}$ types are detected by genotyping with the Ampliquality HPV-Type Express v3.0 kit. The most important 40 types, including low, probable high and high risk groups, are determined. HPV Types in the low risk group are Type 6, 11, 40, 42, 43, 44, 54, 55, 61, 62, 64, 71, $72,81,83,84,87,89,90$. HPV Types in the possible highrisk group are Type 26, 53, 66, 67, 68, 69, 70, 73, 82. HPV Types in the high risk group are Type 16, 18, 31, 33, 35, 39, $45,51,52,56,58,59$. Eleven patients whose molecular test results indicated high-risk HPV types, possible high risk HPV types and multiple HPV types including at least one high risk hpv were excluded from the study. Five patients with recurrent condylomas during the 3-month followup period were treated with laser and excluded from the study. The control group subjects consisted of 86 sexually active and healthy women who were also screened for HPV using molecular testing of cervical smear samples, and six women who tested positive for HPV DNA were excluded from the study. All of the patients were unvaccinated.

As a result, 76 vulvar condyloma patients and 80 controls were included in the study. The study flow is shown in Figure 1.

All patients and controls were evaluated with Female Sexual Function Index (FSFI) and Beck Depression Inventory (BDI) at 0 and 3 months of the study.

\section{Female Sexual Function Index (FSFI)}

The structure of FSFI is made up of 19 questions consisted of six domains: desire, arousal, lubrication, orgasm, satisfaction, and pain. Items are scored on a five-point Likert scale. The raw scores from domains are multiplied by 0.6 for desire, by 0.3 for arousal and lubrication, and by 0.3 for orgasm, satisfaction, and pain. The total score is obtained by adding the raw scores from each domain.
The highest total score that can be obtained is 36.0 , while the lowest is 2.0. Higher scores mean healthier sexual functions. In our study, we used the test validated for the Turkish language by Aygin and Aslan (8).

\section{Beck Depression Inventory (BDI)}

$\mathrm{BDI}$ is a scale that consists of 21 multiple-choice questions. The items are scored on a 0-3 point Likert scale and are designed to measure the severity of depression. Higher scores mean more severe depression. The validation and translation of the scale into Turkish was done by Hisli (9).

\section{Statistical Analysis}

The strength of the study was calculated using the FSFI scores and BDI scores according to the data collected from Russ Lenth's power and sample size analysis module and another reference study (10). The calculated sample size was 52 for each group. After a calculation of $76+80,156$ participants were recruited, and the strength of the study was $95 \%$ for a $5 \%$ type- 1 error. The clinical characteristics of both groups were compared with Statistical Package for Social Sciences (SPSS) for Windows, version 22 (SPSS Inc. IL, USA). The normality of data distribution was tested with the Kolmogorov-Smirnov test. The reliability statistics of the FSFI and BDI were tested with the Cronbach Alpha test. Data were presented as mean \pm SD for continuous variables. The independent samples $t$-test was used to evaluate the variable differences between groups. The dependent $\mathrm{t}$-test was used to evaluate the variation of variables within the group. Mann-Whitney $\mathrm{U}$ test and Bonferroni correction were used for nonnormally distributed results. $\mathrm{P}<0.05$ values were considered statistically significant. The Cronbach Alpha value of the FSFI and BDI scoring was calculated as 0.941 and 0.882 , respectively.

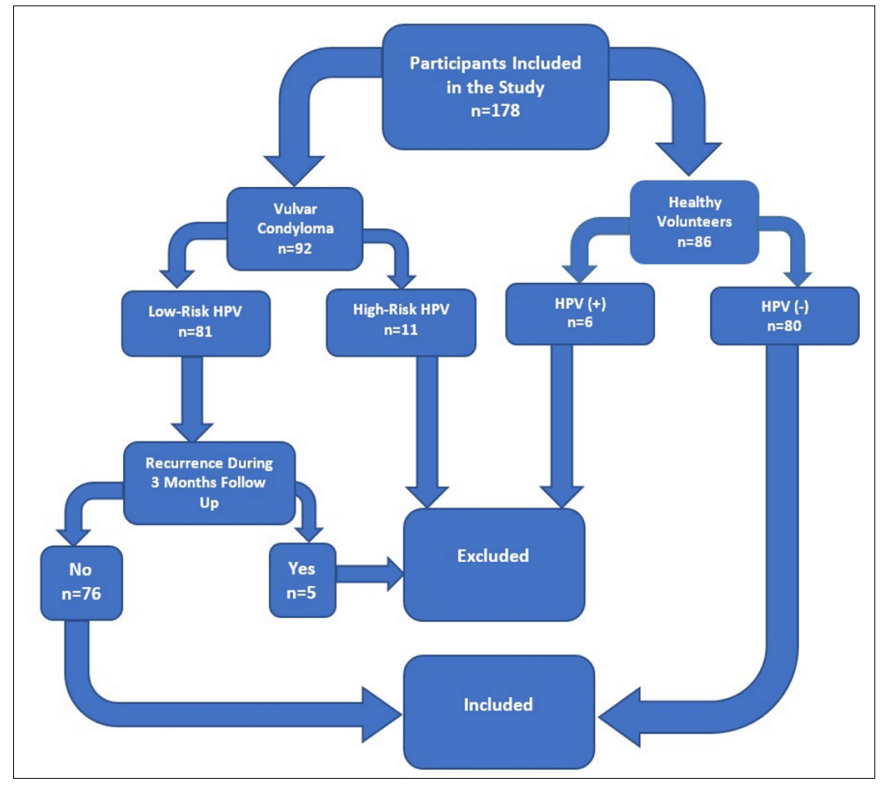

Figure 1. Study diagram 


\section{RESULTS}

There was no significant difference between the groups in terms of age, age of first coitus, preferred contraception methods and education levels $(p>0.05)$. However, a significant difference was observed between the two groups in terms of parity and smoking $(\mathrm{p}=0.001$ and $\mathrm{p}=0.01$ respectively). Demographic data of the participants are presented in Table 1. HPV Genotype distribution of condylomas are HPV Type $6(n=40 ; 52.6 \%)$, HPV Type 11 $(\mathrm{n}=20 ; 26.3 \%)$, HPV Type 6 and Type $11(\mathrm{n}=10 ; 13.1 \%)$, Other Low-Risk HPV Types ( $\mathrm{n}=6 ; 7.8 \%$ ).

The relationship between the patients and controls regarding the evaluation with FSFI and BDI scales at the initial visit (0-month) and in the $3^{\text {rd }}$-month followup (3-month) were presented in Table 2. As seen in the table, a significant difference was observed between the two groups in terms of all FSFI subgroups and total FSFI score, except for the pain subdomain at both 0 and 3 rd months. There was no significant difference between the groups in terms of BDI scores at either 0 or 3rd months.

When the groups were evaluated in terms of 3-month change within themselves, there was no significant difference between the 0 and 3-month FSFI scores of both the patients in the condyloma group and the patients in the control group ( $p>0.05)$. When the BDI scores of the patients in the condyloma group were compared, a significant decrease was observed at 0 and 3 months, and this difference was statistically significant $(\mathrm{p}=0.002)$. However, there was no significant difference between the BDI scores of the patients in the control group at 0 and 3 months ( $p>0.05)$. The relationships within the groups regarding the evaluation with FSFI and BDI scales at the initial visit (0-month) and in the 3rd-month follow-up (3-month) were presented in Table 3.

\begin{tabular}{|lccc|}
\hline Table 1. Demographic data & & & \\
\hline Demographic data & $\begin{array}{c}\text { Condyloma } \\
(\mathbf{n}=7 \mathbf{6})\end{array}$ & $\begin{array}{c}\text { Control } \\
(\mathbf{n}=\mathbf{8 0})\end{array}$ & $\mathbf{P}$ \\
Age & $31.61 \pm 6.42$ & $31.74 \pm 5.62$ & $>0.05^{\mathbf{a}}$ \\
Age at first coitus & $21.34 \pm 2.87$ & $21.95 \pm 3.33$ & $>0.05^{\mathbf{a}}$ \\
Parity & & & $\mathbf{0 . 0 0 1}^{\mathbf{b}}$ \\
0 & 44 & 23 & \\
1 & 11 & 26 & \\
2 & 13 & 29 & \\
$\geq 3$ & 8 & 2 & \\
Contraception & & & $>0.05^{\mathrm{b}}$ \\
Condom & 27 & 24 & \\
Combined oral contraceptive & 9 & 11 & \\
Intrauterine device & 13 & 10 & \\
Other & 4 & 8 & \\
None & 23 & 27 & \\
Smoking & & & $\mathbf{0 . 0 1}^{\mathbf{b}}$ \\
Yes & 48 & 34 & \\
No & 28 & 46 & \\
Education & & & $>0.05^{\mathrm{b}}$ \\
Primary school & 6 & 2 & \\
Secondary school & 14 & 9 & \\
High school & 15 & 27 & \\
University & 32 & 37 & \\
Masters degree & 7 & 4 & \\
Doctorate & 2 & 1 & \\
HPV Genotype & & & \\
HPV 6 & 40 & & \\
HPV 11 & 20 & & \\
HPV 6\&11 & 10 & & \\
Other Low-Risk HPV & 6 & & \\
\hline a: Independent Samples t-Test, b: Mann Whitney U Test & & \\
& & & \\
\end{tabular}

\begin{tabular}{|c|c|c|c|c|c|c|}
\hline \multirow{2}{*}{$\begin{array}{l}\text { FSFI }^{\mathbf{a}} \\
\text { Domains }\end{array}$} & \multicolumn{3}{|c|}{ 0-Month } & \multicolumn{3}{|c|}{ 3-Month } \\
\hline & $\begin{array}{l}\text { The Condyloma Group } \\
(n=76)\end{array}$ & $\begin{array}{c}\text { The Control Group } \\
(\mathbf{n}=\mathbf{8 0 )}\end{array}$ & $\mathbf{P}^{\mathbf{c}}$ & $\begin{array}{l}\text { The Condyloma Group } \\
(n=76)\end{array}$ & $\begin{array}{c}\text { The Control Group } \\
(\mathbf{n}=\mathbf{8 0 )}\end{array}$ & $\mathbf{P}^{c}$ \\
\hline Desire & $3.02 \pm 1.27$ & $3.86 \pm 1.13$ & 0.001 & $3.14 \pm 0,96$ & $3.92 \pm 1.01$ & 0.001 \\
\hline Arousal & $3.34 \pm 1.50$ & $4.01 \pm 1.60$ & 0.008 & $3.41 \pm 1.44$ & $4.03 \pm 1.51$ & 0.010 \\
\hline Lubrication & $3.52 \pm 1.55$ & $4.09 \pm 1.38$ & 0.017 & $3.57 \pm 1.44$ & $4.05 \pm 1.29$ & 0.031 \\
\hline Orgasm & $3.52 \pm 1.83$ & $4.41 \pm 1.68$ & 0.002 & $3.56 \pm 1.72$ & $4.38 \pm 1.60$ & 0.003 \\
\hline Satisfaction & $3.59 \pm 1.83$ & $4.53 \pm 1.62$ & 0.001 & $3.64 \pm 1.73$ & $4.51 \pm 1.54$ & 0.001 \\
\hline Pain & $2.59 \pm 1.61$ & $2.64 \pm 1.53$ & 0.842 & $2.62 \pm 1.51$ & $2.65 \pm 1.42$ & 0.908 \\
\hline FSFI Total & $19.76 \pm 7.92$ & $23.56 \pm 5.80$ & 0.001 & $19.97 \pm 7.06$ & $23.55 \pm 5.49$ & 0.001 \\
\hline BDI ${ }^{\mathrm{b}}$ Total & $17.41 \pm 9.97$ & $16.85 \pm 10.27$ & 0.731 & $16.16 \pm 9.51$ & $16.96 \pm 9.88$ & 0.605 \\
\hline
\end{tabular}

\begin{tabular}{|c|c|c|c|c|c|c|}
\hline \multirow{2}{*}{ FSFI ${ }^{a}$ Domains } & \multicolumn{3}{|c|}{ Condyloma } & \multicolumn{3}{|c|}{ Control } \\
\hline & 0-Month $(n=76)$ & 3-Month $(n=76)$ & $\mathbf{P}^{\mathrm{c}}$ & 0-Month $(n=76)$ & 3-Month $(n=80)$ & $\mathbf{P}^{\mathrm{c}}$ \\
\hline Desire & $3.02 \pm 1.27$ & $3.14 \pm 0.96$ & 0.104 & $3.86 \pm 1.13$ & $3.92 \pm 1.01$ & 0.270 \\
\hline Arousal & $3.34 \pm 1.50$ & $3.41 \pm 1.44$ & 0.135 & $4.01 \pm 1.60$ & $4.03 \pm 1.51$ & 0.320 \\
\hline Lubrication & $3.52 \pm 1.55$ & $3.57 \pm 1.44$ & 0.070 & $4.09 \pm 1.38$ & $4.05 \pm 1.29$ & 0.090 \\
\hline Orgasm & $3.52 \pm 1.83$ & $3.56 \pm 1.72$ & 0.117 & $4,41 \pm 1,68$ & $4,38 \pm 1,60$ & 0,176 \\
\hline Satisfaction & $3,59 \pm 1,83$ & $3,64 \pm 1,73$ & 0,145 & $4.53 \pm 1.62$ & $4.51 \pm 1.54$ & 0.339 \\
\hline Pain & $2.59 \pm 1,61$ & $2.62 \pm 1.51$ & 0.283 & $2.64 \pm 1.53$ & $2.65 \pm 1.42$ & 0.691 \\
\hline FSFI Total & $19.76 \pm 7.92$ & $19.97 \pm 7.06$ & 0.194 & $23.56 \pm 5.80$ & $23.55 \pm 5.49$ & 0.903 \\
\hline BDI $^{\mathrm{b}}$ Total & $17.41 \pm 9.97$ & $16.16 \pm 9.51$ & 0.002 & $16.85 \pm 10.27$ & $16.96 \pm 9.88$ & 0.690 \\
\hline
\end{tabular}




\section{DISCUSSION}

HPV infection, which is the most common sexually transmitted disease in the world, has a prevalence of approximately $11-12 \%$ globally $(1,11)$. Mostly low, rarely high-risk HPV types are responsible for anogenital condylomas. HPV infection can cause psychogenic effects by increasing fear and anxiety due to its oncogenic potential. Because condylomas can recur and cause pain during sexual intercourse, they can distract women from sexuality by being psychologically depressing (12).

Although there have been many previous studies on HPV positivity, HPV-related cervical precancerous lesions, sexual dysfunction, depression, marital relationship status, and anxiety, there number of studies on anogenital warts due to low-risk HPV types is insufficient $(6,12-20)$.

Anogenital warts negatively affect the libido and cause sexual dysfunction because of their apparent recurrence tendency and challenges it poses on the intimacy, such as shaking self-confidence and questioning the partner loyalty $(10,21-23)$.

Embarrassment due to the fact that HPV infection is a sexually transmitted disease, fear of stigma, relationship problems with the partner, anxiety due to the oncogenic potential of the virus, and the fear of infecting the partner, may cause a decrease in sexual desire, depression, and anxiety $(23,24)$.

The high number of nullipars in the condyloma group in our study compared to the control group can be explained by the variations in HPV infection prevalences in different ages. It is known that HPV infection is most common in women under the age of 25; the prevalence decreases with age before peaks again after the age of 45 (25). The presence of many nullipars among the condyloma patients in the current study can thus be explained by the age distribution in the groups as the rates of patients and controls under 25 years old were $34.21 \%$ and $18.75 \%$, respectively.

In a review by Kaderli et al. (26), a relationship between smoking and the occurrence of anogenital HPV infection and the anogenital wart was determined. In our study, consistent with previous studies, the rate of smoking in the condyloma group was significantly higher than in the control group.

A review by Lam et al. (27) indicated that people who used condoms regularly had a lower risk of being infected with HPV. In our study, the preference for condom use was similar in both groups. After the diagnosis of condyloma, those who did not use condoms before might have started to use condoms. Another reason might be the insufficient sample size. Studies with larger samples might demonstrate that condyloma patients are people who prefer condoms less.
Dinh et al. (28) reported that HPV Types 6 and 11 were responsible for more than $90 \%$ of the condyloma cases. Wiley et al. (29) reported that external condyloma usually occurred with low-risk HPV types, especially Type 6 and Type 11. In our study, the distribution of the HPV type was consistent with the results of previous studies.

Elesawy et al. (21), who examined the relationship between the anogenital wart and sexual dysfunction, found sexual dysfunction in $98 \%$ of the participants. The FSFI scores of all subgroup parameters in the condyloma group in our study were lower than those of the control group at both the 0 - and 3 -month. The differences in the subgroups except the pain were statistically significant.

Ma et al. (30) used the FSFI scale in patients with benign cervical pathologies and healthy controls. The prevalence of sexual pain in patients with benign cervical pathologies was lower than that of the controls. The researchers could not interpret their results and suggested that other studies with larger sample sizes were needed.

In an Egyptian study by Elesawy et al. (21), subjects with a history of condyloma for at least three months were included and compared with a healthy control group by using the FSFI test. A significant difference was observed in the control group regarding the FSFI total score. The average FSFI score in our study was two points higher than the average score observed in the study by Elesawy et al. The difference might be due to the fact that the patients in our patient group were started treatment as soon as they were diagnosed, and there were no active and visible condylomas during the study period.

In a Turkish study, Ilgen et al. (31) used FSFI in HPV positive and negative patients. Although the scores of the HPV positive group were lower than those of the control group, the difference was not statistically significant. In contrast, Mercan et al. (32) used the Arizona Sexual Experience Scale to compare the HPV positive patients and the controls, and significantly lower scores in all tested domains (desire, arousal, genital lubrication, orgasm experience, and satisfaction) were observed in the HPV group compared to the control group.

Many studies have addressed the psychological effects of anogenital warts, cervical dysplasia, and HPV positivity on male and female patients. In a study conducted in Iran, Nahidi et al. (22) compared condyloma patients with a control group. The marital relationships of condyloma patients, especially those with a history of previous condyloma treatment, were observed. With the prolongation of the disease, deterioration in marital relations and an increase in conflicts between couples were found. 
McCaferry et al. (15) compared women who had cervical screening and tested positive and negative for HPV and found that HPV-positive women showed more severe depressive symptoms compared to the controls. Mercan et al. (32), who compared HPV-positive patients with a control group from a region with a high socio-cultural background in Istanbul, found a significant difference in $\mathrm{BDI}$ results between the groups. In another study conducted by Uzun et al. (33) in a different region of Istanbul, no significant difference in BDI scores was observed between the HPV positive and the negative groups.

The mean BDI score of the condyloma group was higher than that of the control group; however, the difference was not statistically significant. When the BDI test was used for evaluating the condyloma patients three months after the initiation of the treatment, a statistically significant decrease in the depression severity compared to the 0 -month was observed. Similar to the FSFI scores, the score improvement might be due to the absence of visible condylomas and the reduction in the pressure of oncogenicity in high-risk HPV. Based on this observation, it can be hypothesized that the depression seen in HPV infection might be related to the oncogenic potential of HPV. Moreover, it could be contemplated that the likelihood and severity of depression would be less when the possibility of high-risk HPV disappears.

The discrepancy between our BDI scores and previous literature results might be due to the use of different tests or to the socio-cultural differences of the places where the studies were conducted. As the awareness about the disease increases in regions with high educational levels, it could be expected that the severity of depression in patients would be higher than the controls. Our study was conducted in a region with high socio-cultural background. Due to the high level of awareness about the disease and the lack of the oncogenic risk of the existing condyloma, no significant difference in BDI scores was observed between the groups. Moreover, even after the detection of low-risk HPV, an improvement in scores might have been observed. When the BDI scale was used again in the 3-month, the difference in the mean score was found to be statistically significant.

Having a healthy control group is one of the strengths of our study. Patients with high-risk HPV types were excluded from the study to remove the oncogenic risk of HPV in the condyloma group, which was a major concern. Besides, excluding recurrent patients from the study enabled us to measure the effect of "only condyloma diagnosis" on the individual, with no recurrences. Treatment of patients as soon as they are diagnosed in addition to not following an active condyloma case during the study has provided us with the opportunity to evaluate the effects of "exposure to
HPV virus" on sexuality and psychological state rather than the physical disadvantages. The use of scales translated and validated in the Turkish language is another strength of our study.

In order to prevent bias in the study, all patients who met the criteria determined at the time of the study were included in the study group. Withdrawal bias did not occur as there was no withdrawal while the study was in progress.

One of the weaknesses of our study is that the evaluation period as short as three months. If this period were longer, we might observe a more significant improvement in sexual functions and depression severity. One of the other weaknesses of the study is that the participants consisted of patients taken care of in private health institutions and did not reflect the general public.

Anogenital condylomas have serious effects on the sexual and psychogenic life of women. In order to evaluate those effects of condylomas, different studies with larger sample sizes and other scales are needed.

\section{CONCLUSION}

HPV infection and condylomas, even with the lowrisk HPV types, have a negative effect on female sexual functions and psychogenic status.

\section{ETHICAL DECLARATIONS}

Ethics Committee Approval: This cross-sectional study was approved by the İstanbul Gelişim University Ethics Committee (Date: 11.09.2020, Decision No: 2020-24-03).

Informed Consent: Before the study, all participants were informed, and written consent was obtained.

Referee Evaluation Process: Externally peer-reviewed.

Conflict of Interest Statement: The authors have no conflicts of interest to declare.

Financial Disclosure: The authors declared that this study has received no financial support.

Author Contributions: All of the authors declare that they have all participated in the design, execution, and analysis of the paper, and that they have approved the final version.

\section{REFERENCES}

1. Centers for Disease Control and Prevention. Genital HPV infection-CDC fact sheet. Centers for Disease Control and Prevention 2017. https://www.cdc.gov/std/hpv/hpv-Fs-July-2017. pdf

2. Münger K, Baldwin A, Edwards KM, et al. Mechanisms of Human Papillomavirus-Induced Oncogenesis. J Virol 2004; 78: 11451-60.

3. Melia M. Human papillomavirus (HPV). The Johns Hopkins University, 2017. https: //www.hopkinsguides.com/hopkins/ view/Johns_Hopkins_ABX_Guide/540278/1/Human_ papillomavirus_HPV_. 
4. Gravitt PE, Peyton CL, Apple RJ, Wheeler CM. Genotyping of 27 human papillomavirus types by using L1 consensus PCR products by a single-hybridization, reverse line blot detection method. J Clin Microbiol 1998; 36: 3020-7.

5. Ozgul N, Tuncer M, Abacioglu M, Gultekin M. Estimating prevalence of genital warts in Turkey: Survey among KETEMaffiliated gynecologists across Turkey. Asian Pacific J Cancer Prev 2011; 12: 2397-400.

6. Graziottin A, Serafini A. HPV infection in women: Psychosexual impact of genital warts and intraepithelial lesions. J Sex Med 2009; 6: 633-45

7. Morin C, Bouchard C, Brisson J, Fortier M, Blanchette C, Meisels A. Human papillomaviruses and vulvar vestibulitis. Obstet Gynecol 2000; 95: 683-7.

8. Aygin D, Eti Aslan F. The Turkish adaptation of the female sexual function index. Turkiye Klin J Med Sci 2005; 25: 393-9.

9. Şahin NH. Beck depresyon envanterinin universite ogrencileri icin gecerliligi ve guvenirligi. Psikol Derg 1989; 7: 3-13.

10. Parkpinyo N, Chayachinda C, Thamkhantho M. Factors associated with sexual dysfunction in women experiencing anogenital warts at Siriraj hospital. J Med Assoc Thail 2020; 103: 359-64.

11. Bruni L, Diaz M, Castellsagué X, Ferrer E, Bosch FX, De Sanjosé S. Cervical human papillomavirus prevalence in 5 continents: Metaanalysis of 1 million women with normal cytological findings. J Infect Dis 2010; 202: 1789-99.

12. Waller J, McCaffery K, Kitchener H, Nazroo J, Wardle J. Women's experiences of repeated HPV testing in the context of cervical cancer screening: A qualitative study. Psychooncology 2007; 16 196-204.

13. Bennett KF, Waller J, Ryan M, Bailey JV, Marlow LAV. Concerns about disclosing a high-risk cervical human papillomavirus (HPV) infection to a sexual partner: A systematic review and thematic synthesis. BMJ Sex Reprod Heal 2019; 47: 17-26.

14. Filiberti A, Tamburini M, Stefanon B, et al. Psychological aspects of genital human papillomavirus infection: A preliminary report. J Psychosom Obstet Gynecol 1993; 14: 145-52.

15. McCaffery K, Waller J, Forrest S, Cadman L, Szarewski A, Wardle J. Testing positive for human papillomavirus in routine cervical screening: Examination of psychosocial impact. BJOG An Int J Obstet Gynaecol 2004; 111: 1437-43.

16. McCaffery K, Waller J, Nazroo J, Wardle J. Social and psychological impact of HPV testing in cervical screening: A qualitative study. Sex Transm Infect 2006; 82: 169-74.

17. Nagele E, Reich O, Greimel E, Dorfer M, Haas J, Trutnovsky G. Sexual activity, psychosexual distress, and fear of progression in women with human papillomavirus-related rremalignant genital lesions. J Sex Med 2016; 13: 253-9.

18.Özçelik B, Serin IS, Gökahmetoğlu S, Başbuğ M, Erez R. Human papillomavirus frequency of women at low risk of developing cervical cancer: A preliminary study from a Turkish university hospital. Eur J Gynaecol Oncol 2003; 24: 157-9.

19. Sakin Ö, Uzun SB, Koyuncu K, Giray B, Akalın EE, Anğın AD. Cervix human papilloma virus positivity: Does it cause sexual dysfunction? J Turkish Soc Obstet Gynecol 2020; 16: 235-41.

20. Vriend HJ, Nieuwkerk PT, van der Sande MAB. Impact of genital warts on emotional and sexual well-being differs by gender. Int J STD AIDS 2014; 25: 949-55.

21.El-esawy F, Ahmed H. Effect of Genital Warts on Female Sexual Function and Quality of Life: An Egyptian Study. Hum Androl 2017; 7: 58-64.

22. Nahidi M, Nahidi Y, Kardan G, et al. Evaluation of Sexual Life and Marital Satisfaction in Patients with Anogenital Wart. Actas Dermosifiliogr 2019; 110: 521-5.

23. Scrivener L, Green J, Hetherton J, Brook G. Disclosure of anogenital warts to sexual partners. Sex Transm Infect 2008; 84: 179-82.
24.Waller J, Marlow LAV, Wardle J. The association between knowledge of HPV and feelings of stigma, shame and anxiety. Sex Transm Infect 2007; 83: 155-9.

25. de Sanjosé S, Diaz M, Castellsagué X, et al. Worldwide prevalence and genotype distribution of cervical human papillomavirus DNA in women with normal cytology: a meta-analysis. Lancet Infect Dis 2007; 7: 453-9.

26. Kaderli R, Schnüriger B, Brügger LE. The impact of smoking on HPV infection and the development of anogenital warts. Int J Colorectal Dis 2014; 29: 899-908.

27.Lam JUH, Rebolj M, Dugué PA, Bonde J, von Euler-Chelpin M, Lynge E. Condom use in prevention of human papillomavirus infections and cervical neoplasia: Systematic review of longitudinal studies. J Med Screen 2014; 21: 38-50.

28. Dinh TH, Sternberg M, Dunne EF, Markowitz LE. Genital warts among 18- to 59-year-olds in the United States, National Health and Nutrition Examination Survey, 1999-2004. Sex Transm Dis 2008; 35: 357-60.

29. Wiley DJ, Douglas J, Beutner K, et al. External genital warts: Diagnosis, treatment, and prevention. Clin Infect Dis 2002; 35: S210-24.

30. Ma J, Kan Y, Zhang A, et al. Female sexual dysfunction in women with non-malignant cervical diseases: A study from an urban Chinese sample. PLoS One 2015; 10: e0141004.

31.Ilgen O. Sexual dysfunction in women who are human papillomavirus positive. Reprod Med Gynecol Obstet 2020; 5: $1-4$.

32. Mercan R, Mercan S, Durmaz B, et al. Sexual dysfunction in women with human papilloma virus infection in the Turkish population. J Obstet Gynaecol (Lahore) 2019; 39: 659-63.

33. Uzun SB, Sakin Ö, Hüseyin Ç, Şimsek EE. The effects of HPV test on anxiety, emotion and depression in women. J Acad Res Med 2020; 10: 149-54. 